\title{
Surgical Excision of Ischiorectal Fossa Tumors
}

\author{
Javier Die Trill*, Juan Carlos García, Irene Moreno, Juan Diego Pina, Estela Tobaruela, \\ Jose Barquin, Juan Ocaña, Antonio Rey
}

Department of Surgery, Hospital Ramón y Cajal, Madrid, Spain

Email: *javierdie@hotmail.com

How to cite this paper: Trill, J.D., García, J.C., Moreno, I., Pina, J.D., Tobaruela, E., Barquin, J., Ocaña, J. and Rey, A. (2016) Surgical Excision of Ischiorectal Fossa Tumors. Surgical Science, 7, 461-465. http://dx.doi.org/10.4236/ss.2016.710062

Received: November 17, 2015

Accepted: October 16, 2016

Published: October 19, 2016

Copyright $\odot 2016$ by authors and Scientific Research Publishing Inc. This work is licensed under the Creative Commons Attribution International License (CC BY 4.0).

http://creativecommons.org/licenses/by/4.0/ (c) † Open Access

\begin{abstract}
Background: Ischiorectal Fossa Tumors are rare and their management has not been protocolized. Patients: We retrospectively review four consecutive cases treated in our department, from January 2015 to July 2015. All of them were discussed in a multidisciplinary team meeting. None of them were secondary to an inflammatory process. Results: A Magnetic Resonance Imaging was performed in all the four patients, and as it was not a malignant diagnosis made in any of them, we proceeded to resecate the lesions. None biopsies were performed and the benign diagnoses were confirmed by the pathologist. All the patients underwent a local posterior or perineal approach, because all the lesions (epidermoid cyst, hamartoma, lipoma and an aggressive angiomyxoma) were localized purely in the ischiorectal fossa, under the levator ani muscle and not invading any adjacent structures. In all of them, an R0 resection was performed. Conclusions: Ischiorectal fossa tumors are rare and there are few cases already published. Non-inflammatory lesions located in the ischiorectal fossa, with none invasion of rectum or levator ani muscle, are mainly benign lesions prone to their complete excision by a posterior approach. Biopsy is not always necessary unless there's a suspicion of a malignancy or invasion of adjacent structures, and only in that case a biopsy should be made, because in some of them, a neo- adjuvant treatment can be useful to reduce the tumor and to perform an R0 resection.
\end{abstract}

\section{Keywords}

Ischiorectal Fossa Tumors, Aggressive Angiomyxoma

\section{Introduction}

Ischiorectal fossa tumors are rare, and only a few cases have been published [1]-[7]. This area is anatomically defined superiorly by the levator ani, laterally by the obturator internal muscle and the obturator fascia, medially by the external sphincter muscles, anteriorly by the superficial and deep transverse perineal muscle, and inferiorly by the 
skin of the perineum [1].

A large variety of pathological lesions are likely to occur in this area [3] [4], and it's not accessible through an abdominal approach. Depending on the size, the location defined by a pelvic MRI and sometimes by the histology, a posterior, local perineal approach, can be done as in our patients. In other cases, a more complex posterior approach is needed as is appointed by Prof. Karakousis team [2], with gluteal, sacral or levator resections; or a combined abdomino-perineal approach [2]-[7].

We review the four cases operated in our hospital this year.

\section{Material and Methods}

We retrospectively describe four patients with an ischiorectal fossa tumors operated at our department from January to December 2015.

A pelvic MRI was performed and a surgical R0 resection was performed in all of them by a posterior/perineal approach.

We also make a brief review of the most recent articles by a PubMed search.

\section{Results}

Four consecutive patients presented a non-inflammatory benign ischiorectal mass and they were all operated at our department from January to December 2015.

Their characteristics are summarized in Table 1.

All the patients had a clearly benign "pathology" based on the MRI findings, and none of them had a percutaneous biopsy.

The patient diagnosed with aggressive angiomyxoma didn't have invasion of any adjacent structure (Figure 1), and was not treated preoperatively with goserelin acetate (GnRH agonist, Zoladex) because a R0 resection could be safely done.

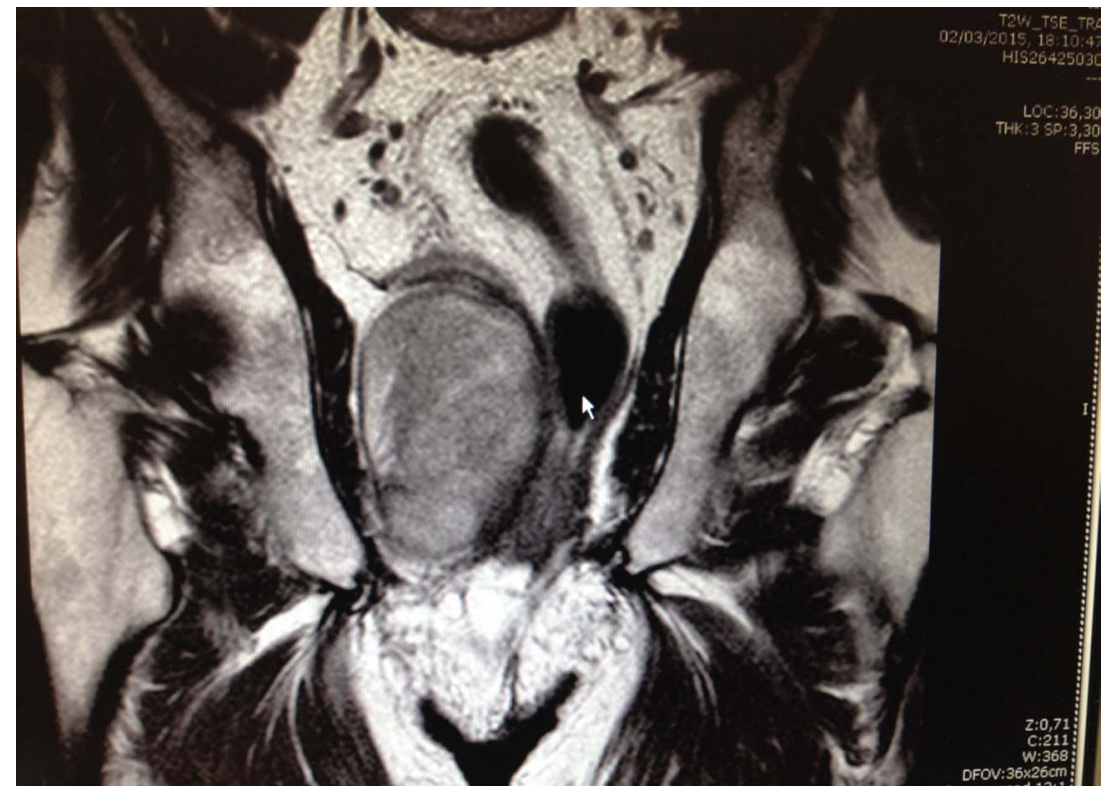

Figure 1. MRI of an aggressive angiomyxoma. 
Table 1. Preoperative data.

\begin{tabular}{|c|c|c|c|c|c|c|}
\hline Patient & Symptoms & $\begin{array}{l}\text { Lesion } \\
\text { Size } \\
(\mathrm{MRI})\end{array}$ & $\begin{array}{l}\text { Invasion of } \\
\text { adjacent } \\
\text { structures } \\
\text { (MRI) }\end{array}$ & $\begin{array}{c}\text { Preop. } \\
\text { Suspicion } \\
\text { of malignancy }\end{array}$ & $\begin{array}{l}\text { Preop. } \\
\text { Biopsy }\end{array}$ & Preop. Diagnostic \\
\hline 1. 37 y.o. $F$ & $\begin{array}{l}\text { Pain } \\
\text { the buttock }\end{array}$ & $13 \times 6 \times 4.2 \mathrm{cms}$ & No & No & No & Benign cyst \\
\hline 2. 72 y.o. $\mathrm{M}$ & $\begin{array}{l}\text { Lump } \\
\text { in the buttock }\end{array}$ & $8 \times 5.1 \times 3.3 \mathrm{cms}$ & No & No & No & $\begin{array}{c}\text { Aggressive } \\
\text { angiomyxoma }\end{array}$ \\
\hline 3.71 y.o F & $\begin{array}{l}\text { Incidental } \\
\text { finding }\end{array}$ & $\begin{array}{c}6.5 \times 5.5 \times 4.9 \\
\mathrm{cms}\end{array}$ & No & No & No & $\begin{array}{l}\text { Multiloculated } \\
\text { dermal cyst } \\
\text { or hamartoma }\end{array}$ \\
\hline 4. 64 y.o F & $\begin{array}{c}\text { Lump } \\
\text { in th buttock }\end{array}$ & $5.4 \times 6 \times 3.4 \mathrm{cms}$ & No & No & No & Lipoma \\
\hline
\end{tabular}

y.o. = years old; $F=$ female; $M=$ male.

All the patients had a surgical resection by a local posterior/perineal approach and a drain was placed at the end of the procedure. There was no need of resection of any adjacent structures and all of them were R0 resections. There were no complications except a wound infection in the patient diagnosed of a hamartoma. All of them were discharged at day 3 after the surgery. There's a short follow-up to talk about recurrence specially in the aggressive angiomyxoma case. But there weren't any recurrences (Figure 2 and Table 2).

\section{Discussion}

Tumors of the ischiorectal fossa are a big challenge for a surgeon, first because is a rare condition, the literature is based on case reports and small case series; and second because of the difficult accesibility of their location.

The preoperative diagnosis is mainly based on MRI features [1] [2] [5]-[7], if the radiological appearance of the lesion is diagnostic or clearly benign, a biopsy is not necessary, unless a neoadjuvant treatment is required to reduce the size of the tumor or to reduce local invasion in the locally aggressive angiomyxoma [7]. Aggressive angiomyxoma has some radiological features described in some papers. In our case the aggressive angiomyxoma didn't invade any adjacent structure.

Biopsy is needed if there's not a clearly benign diagnosis based on MRI. In some cases, as it's described by Prof. Mortensen's team [7], the biopsy can alter the management of the patient, and some cases of aggressive angiomyxoma can be treated initially with goserelin acetate (GnRH agonist, Zoladex), some GIST with imatinib, and some desmoids fibromatosis with tamoxifen and sulindac observing sometimes a reduction in the size of the lesion or a reduction of the local invasion.

Once a retrorectal tumor is diagnosed most patients require surgery. For benign tumors, this is because of the risk of misdiagnosis, malignant degeneration and symptom progression. Benign tumors such as tailgut cysts may progress to become neuroendocrine tumors or adenocarcinoma, teratomas have a high risk of malignant transforma- 


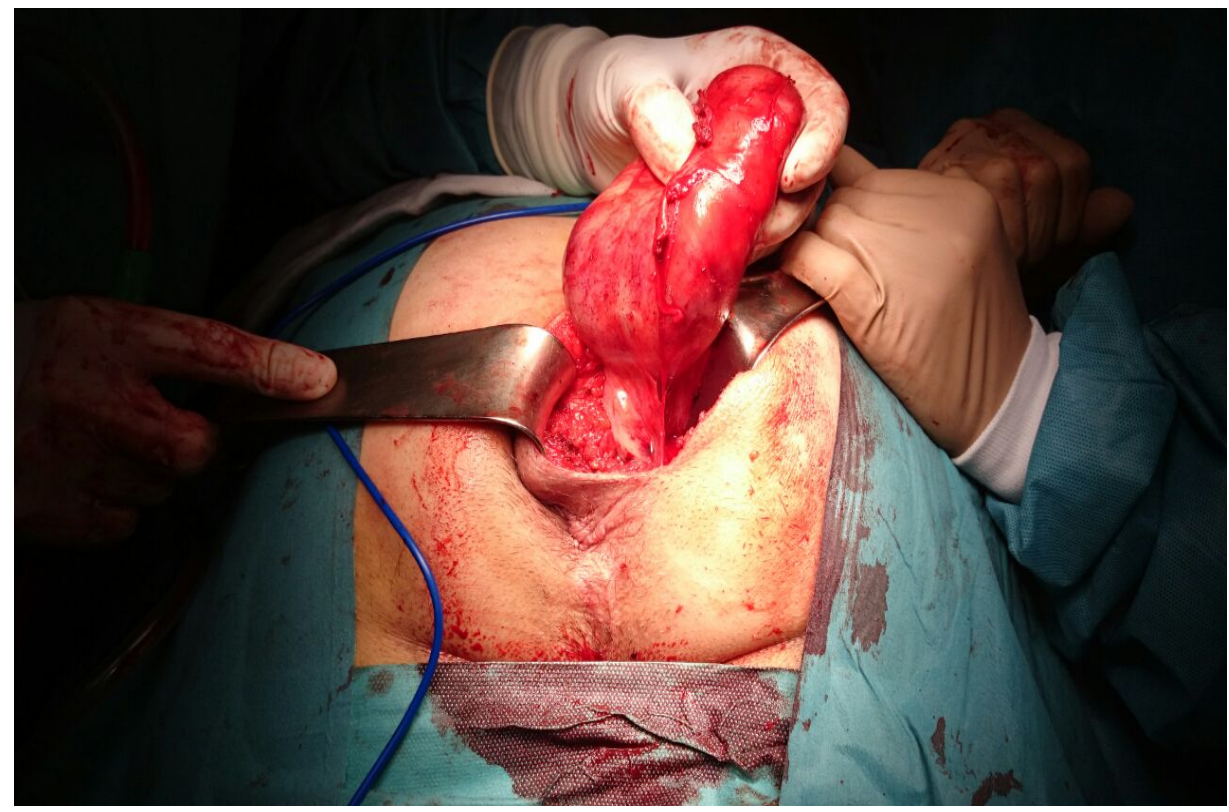

Figure 2. Aggressive angiomyxoma resection.

Table 2. Operative and pathological data.

\begin{tabular}{ccccc}
\hline Patient & Procedure & Histopathology & Margins & Recurrence \\
\hline 1. & Posterior/perineal local approach & Epidermal Cyst & R0 & No \\
2. & Posterior/perineal local approach & Aggressive angiomyxoma & R0 & No (8 months follow-up) \\
3. & Posterior/perineal local approach & Hamartoma & R0 & No \\
4. & Posterior/perineal local approach & Lipoma & R0 & No
\end{tabular}

tion, and myelolipomas have been described in the literature to harbour malignancy despite a benign appearance.

The selection of the surgical approach is an important issue and we must select a posterior approach except if there's a levator ani infiltration or the tumor extends superiorly, in that case an abdomino-perineal approach should be performed. The decision should be based according to the radiological findings.

A R0 resection is the key to avoid local recurrences, and this is of special interest in malignant tumors or locally aggressive tumors such as aggressive angiomyxoma.

We made a local posterior approach in all the four cases, because they were all benign small lesions, but this is not usual, and sometimes is necessary a sacral or a rectal excision as Prof Karakousis team describes so well in his article.

Recently, a group from New Zealand published a 65 patients serie (the largest series published to the date), with a confirmed retrorectal tumors, with a $29 \%$ of malignant tumors. They demonstrated a $95 \%$ sensitivity for differentiating benign from malignant tumors with the MRI. They also performed a biopsy only to the solid lesions, performing surgery only to 27 of the 65 lesions highlighting the importance of the MRI in the management of this lesion [8]. 


\section{Conclusions}

Ischiorectal tumors are a rare condition.

MRI is the key for a good preoperative and intraopertive management of this tumor.

When there's not a clear benign radiological diagnosis, a biopsy has to be done because in some cases with locally aggressive tumors a neoadjuvant treatment can reduce the tumor local invasion.

Local recurrences are sometimes avoided by difficult surgeries where a distal sacrectomy or a rectal resection is necessary that should be done by teams prepared for that surgery. An abdomino-perineal approach is the better approach for ischiorectal tumors that invade levator ani muscle.

\section{References}

[1] Hoeffel, C., Daoud Crema, M., Azizi, L., et al. (2007) Magnetic Resonance Imaging of the Ischiorectal Fossa: Spectrum of Disease. Journal of Computer Assisted Tomography, 31, 251-257. http://dx.doi.org/10.1097/01.rct.0000236419.90019.40

[2] Miller, M., Kulaylat, M., Ferrario, T., et al. (2003) Resection of Tumors of the Ischiorectal Fossa. Journal of the American College of Surgeons, 196, 328-332. http://dx.doi.org/10.1016/S1072-7515(02)01764-7

[3] Cases-Baldó, M.J., Andrés García, B., Pellicer, E., et al. (2011) Angiomixoma agresivo perianal: Diagnóstico y tratamiento. Cirugía Española, 89, 405-406. http://dx.doi.org/10.1016/j.ciresp.2010.05.021

[4] Wanebo, J.E., Malik, J.M., Vanden Berg, S.R., et al. (1993) Malignant Peripheral Nerve Sheath Tumors. A Clinicopathologic Study of 28 Cases. Cancer, 71, 1247-1253. http://dx.doi.org/10.1002/1097-0142(19930215)71:4<1247::AID-CNCR2820710413>3.0.CO; $\underline{2-\mathrm{S}}$

[5] Goldberg, S.M., Gordon, P.H. and Nivatvongs, S. (1980) Essentials of Anorectal Surgery. Lippincott-Raven, Philadelpia, p. 215.

[6] Jao, S.W., Beart Jr., R.W., Spencer, R.J., Reiman, H.M. and Ilstrup, D.M. (1985) Retrorectal Tumors; Mayo Clinic Experience, 1960-1979. Diseases of the Colon \& Rectum, 28, 644-652. http://dx.doi.org/10.1007/BF02553440

[7] Buchs, N., Mortensen, N., Guy, R., et al. (2015) Management of Tumors of the Ischiorectal Fossa: The Role of Percutaneous Biopsy. Diseases of Colon and Rectum, 58, 938-942. http://dx.doi.org/10.1097/DCR.0000000000000438

[8] Hopper, L., Eglinton, T.W., Wakeman, C., Dobbs, B.R., Dixon, L. and Frizelle, F.A. (2015) Progress in the Management of Retro- rectal Tumours. Colorectal Disease, 18, 410-417. http://dx.doi.org/10.1111/codi.13117 
Submit or recommend next manuscript to SCIRP and we will provide best service for you:

Accepting pre-submission inquiries through Email, Facebook, LinkedIn, Twitter, etc. A wide selection of journals (inclusive of 9 subjects, more than 200 journals)

Providing 24-hour high-quality service

User-friendly online submission system

Fair and swift peer-review system

Efficient typesetting and proofreading procedure

Display of the result of downloads and visits, as well as the number of cited articles

Maximum dissemination of your research work

Submit your manuscript at: http://papersubmission.scirp.org/

Orcontact ss@scirp.org 